\section{Counseling Older LGBTQ+ Adults of Color: Relational-Cultural Theory in Practice}

\author{
Christian D. Chan, Camille D. Frank, Melisa DeMeyer, \\ Aishwarya Joshi, Edson Andrade Vargas, Nicole Silverio
}

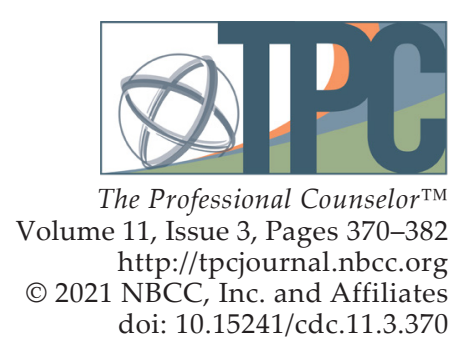

$\otimes$ IPC

Pressional Counselor doi: $10.15241 /$ cdc. 11.3 .370

Lesbian, gay, bisexual, transgender, and queer (LGBTQ+) communities have faced a history of discriminatory incidents with deleterious effects on mental health and wellness. Compounded with other historically marginalized identities, LGBTQ+ people of color continue to experience disenfranchisement, inequities, and invisibility, leading to complex experiences of oppression and resilience. Moving into later stages of life span development, older adults of color in LGBTQ+ communities navigate unique nuances within their transitions. The article addresses the following goals to connect relational-cultural theory (RCT) as a relevant theoretical framework for counseling with older LGBTQ+ adults of color: (a) explication of conceptual and empirical research related to older LGBTQ+ adults of color; (b) outline of key principles involved in the RCT approach; and (c) RCT applications in practice and research for older LGBTQ+ adults of color.

Keywords: relational-cultural theory, theoretical framework, older adults, LGBTQ+, people of color

Multiple forms of oppression have been historically documented across conceptual and empirical literature for the broad spectrum of lesbian, gay, bisexual, transgender, and queer (LGBTQ+) communities across the life span (Chan, 2018; Chan \& Erby, 2018; Meyer, 2014, 2016; Singh, 2013). Further, Black, indigenous, and people of color (BIPOC) have experienced multiplicative deleterious effects combined with psychosocial factors that culminate in racial discrimination and marginalization (David et al., 2019; Sue et al., 2019). Oppression for BIPOC communities and LGBTQ+ communities often cascades across the life span and culminates in a number of health disparities (Choi \& Meyer, 2016; Fredriksen-Goldsen et al., 2015, 2017). Given these complex dimensions with social identities, researchers have expanded their focus to examine social conditions, such as education and health care, to accentuate the needs of older LGBTQ+ adults of color (Howard et al., 2019; Kim et al., 2017). Although researchers have given more attention to LGBTQ+ BIPOC (e.g., Jackson et al., 2020; Velez et al., 2019), older adults within these communities are typically omitted in practice, advocacy, and policy (Kimmel, 2014; Porter et al., 2016; Seelman et al., 2017; South, 2017). Combined with this pattern of exclusion, older LGBTQ+ adults of color are forced to navigate a dearth of resources and complicated climates that fail to properly recognize multiple overlapping forms of racism, heterosexism, genderism, and ageism (Kim et al., 2017; Woody, 2014). Within the counseling profession, gaps in culturally responsive services and advocacy combine with alarming rates of barriers, health disparities, and underutilization of mental health services (Chan \& Silverio, in press; Kim et al., 2017; Lecompte et al., 2021).

Relational-cultural theory (RCT) operates as a cohesive and modern theoretical approach founded on values of feminism, equity, empowerment, and social justice (see Comstock et al., 2008; Duffey \& Trepal, 2016; Hammer et al., 2016; Kress et al., 2018). Instances of disconnection can be prominent at older adult stages of life (Seelman et al., 2017), and RCT offers a purposeful framework for increasing relational

Christian D. Chan, PhD, NCC, is an assistant professor at the University of North Carolina at Greensboro. Camille D. Frank, PhD, NCC, LPC, is a lecturer at Eastern Washington University. Melisa DeMeyer, PhD, NCC, LPC, is an assistant professor and program coordinator at Oregon State University-Cascades. Aishwarya Joshi, MA, NCC, LPC, is a doctoral candidate at Idaho State University. Edson Andrade Vargas, PhD, is a visiting assistant professor at Palo Alto University. Nicole Silverio, MA, NCC, LMHC, LMFT, is a doctoral student at the University of North Carolina at Greensboro. Correspondence may be addressed to Christian D. Chan, 228 Curry Building, Department of Counseling and Educational Development, The University of North Carolina at Greensboro, P.O. Box 26170, Greensboro, NC 27402, cdchan@uncg.edu. 
awareness (Hammer et al., 2016), relational growth (Kress et al., 2018), and investment in professional counseling relationships (Fullen et al., 2020). Given developmental concerns and life span transitions, older LGBTQ+ adults of color can remain disconnected from family, society, institutional resources, and professional counselors (Jones et al., 2018; Mereish \& Poteat, 2015; Seelman et al., 2017). Using an RCT approach accounts for these factors and increases the awareness of disconnections between people and others in their environment (Hammer et al., 2016; Singh \& Moss, 2016). Because of its emphasis on relationships, RCT's focus on mutually fostering growth and dismantling oppression provides a platform for professional counselors to integrate the themes of equity, social justice, and feminism into counseling practice with older LGBTQ+ adults of color (Rausch \& Wikoff, 2017; Singh et al., 2020). RCT demonstrates that intersections of social identities mirror several overlapping forms of oppression and hierarchies of power (Addison \& Coolhart, 2015; Chan \& Erby, 2018; Hammer et al., 2016).

Within this conceptual framework, we intentionally use LGBTQ+ communities to inclusively highlight communities featured across the spectrum of sexuality, affectional identity, and gender identity (Griffith et al., 2017). As counselors address the intersections among social identities, applying philosophical underpinnings of RCT equips them to tackle cultural, social, and contextual barriers that disconnect older LGBTQ+ people of color from society, resources, and health care access. Consequently, this article entails a three-pronged approach: (a) an overview of extant conceptual and empirical research relevant for older LGBTQ+ adults of color; (b) in-depth illustration of key principles within the RCT approach; and (c) RCT applications for counseling practice and research to support older LGBTQ+ adults of color.

\section{Intersections of Older Adults, LGBTQ+ Communities, and Communities of Color}

Scholars across disciplines (e.g., psychology, social work, counseling, sociology, education) continue to explore intersections of racial and ethnic identities in confluence with sexuality, affection, and gender identity (Chan \& Erby, 2018; Jackson et al., 2020; Van Sluytman \& Torres, 2014). Researchers can ostensibly benefit from a gerontological focus to critically examine social conditions and structures sustained by ageism (Chaney \& Whitman, 2020; Kim et al., 2017). The lack of attention to gerontology, ageism, or older adults within LGBTQ+, racial, and ethnic identity research has further underscored the impact of health disparities and social determinants of health (e.g., education, economic resources, career, income) that precipitate an underutilization of mental health services and health care, specifically among LGBTQ+ people of color (Choi \& Meyer, 2016; Du \& Xu, 2016; Fredriksen-Goldsen, 2014; Rowan \& Giunta, 2016; Seelman et al., 2017). Kim and colleagues (2017) specifically observed that race and ethnicity have been historically excluded as variables and outcomes in LGBTQ+ older adult research. Building further on this gap, Woody's (2014) study of African American LGBT elders exemplified the need to address these intersections of identities. In the study, Woody noted that African American LGBT elders consistently faced conflicts in negotiating ethnic and spiritual values together with sexual and gender identities. Outside of oppressive circumstances, older adults already face realities associated with the aging process, health concerns, maintaining an economic standard of living, retirement, and housing barriers related to developmental life tasks and the stages of older adulthood (Brennan-Ing et al., 2014; Choi \& Meyer, 2016; Porter et al., 2016). Several of these concerns coincide with a consistent gap in culturally responsive counseling practices focused on older adults (Chan \& Silverio, in press; Fullen, 2018) and the call to action by Fullen and colleagues (2019) to broaden research evidence in gerontological counseling.

\section{Health Disparities}

As gerontological and health researchers attempt to shed light on the experiences of older LGBTQ+ adults of color, overall trends continue to reveal cultural, social, psychological, and physical implications 
of intersecting forms of oppression. In fact, a study by Kim et al. (2017) documented that African American LGBT elders faced higher rates of lifetime discrimination, which adversely affected their physical and mental health. Similarly, incidents that contribute to the lack of identity affirmation, community networks, and social support exacerbate a number of health disparities and adverse outcomes of mental health (Fredriksen-Goldsen et al., 2013; Seelman et al., 2017; Woody, 2014, 2015). Consistent with patterns in health disparities research, oppression tends to serve as a catalyst for higher prevalence of suicidality among older LGBTQ+ adults of color (Choi \& Meyer, 2016; Meyer, 2014, 2016). In fact, Fullen and colleagues (2018) noted that internalized ageism can predispose older adults to a myriad of mental health issues, symptoms, and increased rates of suicidal ideation. According to Seelman (2019), the combination of responding to discrimination along with barriers to access can significantly increase the mortality rate for older LGBTQ+ adults of color. Conversely, the preservation of cultural identity (Fullen, 2016) and identity affirmation (Fredriksen-Goldsen et al., 2017; Howard et al., 2019; Kim et al., 2017) buffers the effects of oppression and encourages older LGBTQ+ adults of color to seek help and health care.

Older LGBTQ+ adults of color also face disproportionate access to resources, especially adequate and LGBTQ-affirming health care services (Hinrichs \& Donaldson, 2017; Kimmel, 2014). Among the variety of health conditions tied to the aging process, the risk of HIV increases for older LGBTQ+ adults of color as a result of psychosocial factors, such as poverty, stigma, marginalization, and lack of education (Bower et al., 2021; Jones et al., 2018; Karpiak \& Brennan-Ing, 2016; Yarns et al., 2016). Many of these barriers can be traced to the marginalization attached to ageism, classism, racism, genderism, and heterosexism (Brennan-Ing et al., 2014; Robinson-Wood \& Weber, 2016). During this stage, older LGBTQ+ adults of color face drastic changes to mental health based on cumulative interactions with societal stigma and internalized heterosexism and genderism (Correro \& Nielson, 2020; Yarns et al., 2016). Consistently responding to discrimination can eventually culminate in a variety of mental health symptoms (e.g., anxiety, depression) or mental exhaustion (FredriksenGoldsen, 2014; Fredriksen-Goldsen et al., 2013).

\section{Social Isolation, Grief, and Loss}

Compounded with multiple overlapping forms of oppression, older LGBTQ+ adults of color can have a multifaceted experience of social isolation and loss as they transition into the stages of older adulthood (Dzierzewski, 2014). Although older adults generally experience grief and loss as part of the transition in aging (Chaney \& Whitman, 2020; Kampfe, 2015), these experiences are heightened for older LGBTQ+ adults of color as an outcome of navigating racism, heterosexism, and genderism (Bockting et al., 2016; Woody, 2014, 2015). The loss of family, friends, social networks, and intimate partners for older LGBTQ+ adults of color can converge with an overall lack of affirmation and heighten experiences of racial, sexual, and gender discrimination (Seelman et al., 2017). Instances of isolation and loss are pervasive because of the confluence of racism and heterosexism converging in this stage of the life span (Woody, 2015). Woody's (2015) study noted that older African American lesbian women cited the proliferation of racism as a more prominent issue than their experiences with other forms of oppression (e.g., heterosexism). Compounding these losses, barriers to housing and the likelihood of eviction for older LGBTQ+ adults of color can amplify feelings of displacement from communities and society (Brennan-Ing et al., 2014; Robinson-Wood \& Weber, 2016).

Additionally, older LGBTQ+ adults of color consistently contend with coming out across the life span (Hinrichs \& Donaldson, 2017; Mabey, 2011). Experiences of coming out and self-disclosure of these social identities can be complex because of the loss of connections, fear of rejection, and incivility from 
trusted communities of support (Dzierzewski, 2014; Woody, 2014; Yarns et al., 2016). Complicating the range of concerns within the older adult stages, the chronic effects of marginalization can increase risk factors for substance use and addictions as coping mechanisms for older LGBTQ+ adults of color (Bryan et al., 2017; Veldhuis et al., 2017). Substance use and addictions have become a more visible crisis facing these communities, and they can combine with the risks of displacement from social supports and vital community resources (Brennan-Ing et al., 2014; Cloyes, 2016; Rowan \& Giunta, 2016).

\section{The Model of Relational-Cultural Theory (RCT)}

RCT can be used by counselors to reflect experiences with societal forces of oppression (Singh \& Moss, 2016) and social determinants tied to health, connection, and wellness (Hammer et al., 2016). RCT has surfaced as an applicable theoretical approach for older LGBTQ+ adults of color with the most recent uptick of research and scholarship (Mereish \& Poteat, 2015; Singh et al., 2020). Given the core values of RCT generated with social context, authenticity, connection, and social justice, the approach addresses needs, social conditions, barriers, and marginalization experiences for older LGBTQ+ adults of color (Chan \& Erby, 2018; Rausch \& Wikoff, 2017; Singh \& Moss, 2016). The history of RCT provides context for current practice and underscores the foundation of a relationally centered paradigm. The concepts of relational images, growth-fostering relationships, and the central relational paradox inform counseling with clients experiencing such positions of resilience and oppression (Duffey \& Trepal, 2016). The relevance of an RCT approach to a number of client concerns has gained traction as counseling professionals are charged with implementing more culturally responsive approaches (Flores \& Sheely-Moore, 2020; Haskins \& Appling, 2017; Singh et al., 2020). To support RCT's utility, a recent review from Lenz (2016) concluded that empirical research has consistently supported RCT constructs and its use as a framework for understanding client experiences.

\section{Key Principles}

Originally positioned within Miller's (1976) Five Good Things, the principles of RCT in counseling practice have imminently evolved into a robust theoretical framework centered in (a) clarity of self and others, (b) creativity, (c) zest, (d) empowerment, and (e) connection. As Jordan (2000) provided in an influential comprehensive overview of RCT, the main themes for the framework can be summarized in four distinct areas. The first principle posits that people are generally oriented toward growing individually and collectively within their relationships across the life span (Jordan, 2010, 2017), which results in growth-fostering relationships (Miller, 1976; Miller \& Stiver, 1997). Secondly, growth-fostering relationships require mutuality, which is defined as mutual empathy and mutual empowerment (Jordan, 2010; Kress et al., 2018). Because of mutuality in growth-fostering relationships, assessing growth of individuals and relationships is contingent on authenticity, or individual genuineness, as the third component (Duffey \& Trepal, 2016; Jordan, 2000, 2017). Individuals' abilities to represent themselves authentically in their relationships can be a function of this growth (Duffey \& Somody, 2011; Hammer et al., 2016). Because authenticity underpins mutuality and growth-fostering relationships, the fourth area of RCT involves the central relational paradox. The central relational paradox illustrates how the fear of vulnerability reduces authentic expression and maintains disconnections, despite a proclivity for connection with others (Miller \& Stiver, 1997). When mutuality and authenticity are prioritized, professional counselors using RCT assume that conflict can be a normal dynamic in the relationship, in which high-level growth in the relationship involves the ability to actively address this relational difference (Comstock et al., 2008; Duffey, 2007; Jordan \& Carlson, 2013). The primary function of RCT in counseling then focuses on building relational competence (Kress et al., 2018; Singh \& Moss, 2016). 
To build further on these constructs, several researchers have provided a foundation for using RCT with older LGBTQ+ adults of color (Flores \& Sheely-Moore, 2020; Mereish \& Poteat, 2015; Singh \& Moss, 2016). There are cultural, social, and political implications underlying the connection between RCT and older LGBTQ+ adults of color. For example, older LGBTQ+ adults of color are forced to contend with multiple points of disconnection from society through histories of racism, genderism, heterosexism, and ageism. Although multiple forms of oppression can disconnect historically marginalized communities, ageism is distinct because it focuses on marginalizing life transitions (Chaney \& Whitman, 2020; Fullen, 2018). Consequently, older LGBTQ+ adults of color experience a heightened sense of disconnection due to grief and loss, isolation, and lack of social support. Older LGBTQ+ adults of color may likely encounter disconnections from a society that fails to affirm their identities, which precipitates a disconnection to self and underutilization of community resources (Kim et al., 2017; Seelman et al., 2017). Older LGBTQ+ adults of color may face a hierarchy of power and privilege that would impair an authentic connection and movement toward mutuality (Duffey \& Somody, 2011; Hammer et al., 2016; Jordan, 2010). One outcome of this hierarchy is the notion of relational images, in which historically marginalized individuals feel forced to conform to a privileged identity. For instance, an older lesbian woman of color as a client may hold controlling relational images of help-seeking when interacting with a White male counselor possessing multiple privileged identities. In this instance, the client might internalize stereotypes and biases imposed by the counselor. Using RCT explicitly addresses these controlling relational images to challenge the dominant discourse, increase authenticity, and empower connection (Hammer et al., 2016; Haskins \& Appling, 2017).

\section{RCT as a Lens for Conceptualization and Intervention}

The following hypothetical case example underscores the theoretical underpinnings of RCT and illustrates applications of RCT in clinical practice. This case example illustrates a variety of RCT principles to help counselors connect potential experiences of older LGBTQ+ adults of color and the complexity of intersecting forms of oppression. With the overall case study presented, Table 1 synthesizes key principles and applications, supplemental literature, and relevant portions of the case example.

\section{Case Formulation}

Chris, 72 years old, and Hector, 71 years old, have been partnered for 27 years. Chris is a Mexican American bisexual male born in the United States with the pronouns he, him, and his. Hector is a multi-heritage Asian American gay man of Filipino, Norwegian, and Colombian descent with the pronouns he, him, and his. Both Chris and Hector are Catholic and living without disabilities. Chris retired as a social worker when he reached 65 years of age while Hector chose to continue working as a university professor until the previous year at age 70. Chris and Hector recently relocated to live with Chris's daughter from a previous marriage, Ella. Ella welcomed both Chris and Hector into her home as family. Upon the transition to their retirement phase, Chris and Hector began spending most of their time at home, and Ella has checked in with them regularly. They took on new hobbies, including painting, and focused more of their time on relaxation and leisure. Recently, Chris became increasingly concerned with Hector's forgetfulness. Chris became worried about bringing him to social events, as Hector was "absentminded." Although initially excited about the move, Chris realized Hector was struggling with all of the new issues that emerged from the transition. Chris thought about discussing the concerns with his daughter, but he did not want to worry her or embarrass Hector. Chris has felt conflicted about his own internal and external responses. Over the past few months, Chris has felt increasingly isolated and disconnected with Hector while recognizing a decreased lack of enjoyment. 


\section{Table 1}

\section{RCT Applications to Case Example}

\begin{tabular}{|c|c|}
\hline Application & Supporting Literature \\
\hline $\begin{array}{l}\text { Connection is essential to } \\
\text { existence. }\end{array}$ & $\begin{array}{l}\text { Duffey \& Somody, 2011; } \\
\text { Lenz, 2016; Walker \& } \\
\text { Rosen, 2004 }\end{array}$ \\
\hline $\begin{array}{l}\text { Growth-fostering } \\
\text { relationships result in the } \\
\text { Five Good Things: clarity of } \\
\text { self and others, creativity, } \\
\text { zest, empowerment, and }\end{array}$ & $\begin{array}{l}\text { Miller, 1976; Miller \& } \\
\text { Stiver, 1997; Duffey, } \\
\text { 2007; Duffey et al., 2009; } \\
\text { Duffey \& Somody, 2011; } \\
\text { Hammer et al., 2014 }\end{array}$ \\
\hline
\end{tabular}
connection.

The central relational paradox centers around the idea that people long deeply for relationships, but fear of what will happen after engaging in the vulnerability needed for connection provokes people to keep aspects of themselves out of connection.

Central to RCT is the idea that systems of power and privilege, which are pillars in our current society, result in damage to psychological health.

\section{Exploring relational} connection and equity must include an analysis of social context and mechanisms responsible for giving root to oppression.
Jordan, 2010; Jordan \& Carlson, 2013; Miller \& Stiver, 1997; Walker \& Rosen, 2004

Hammer et al., 2014, 2016; Haskins \& Appling, 2017; Trepal et al., 2012
Hammer et al., 2014, 2016; Mereish \& Poteat, 2015

\section{Relevance to Case Example}

Practitioners can identify the possible connections Chris and Hector have with each other and with their family. In addition, practitioners can also cite the connection they have with the clients Chris and Hector. Practitioners can particularly note the disconnect they have experienced as society has emerged with transitions and multiple overlapping forms of oppression.

Practitioners can work with Chris and Hector to search for strengths and reinvigorate their energy in each other during this transition and stage of their lives. Although Chris and Hector initially struggled with the transition, practitioners can ascertain new types of hobbies and activities they can create together. Such creative activities might elicit more nuanced meaning. Practitioners can also highlight the methods and actions in which Chris and Hector have been resilient in the face of adversity in association with societal and interpersonal discrimination.

Practitioners can focus on how the transition affected Chris and Hector's connection to each other. It is possible that the transition altered their interpretation of connection, given that they are now living with Chris's daughter, Ella. Hector could have also felt a sense of loss with his retirement, which led to new ways of thinking and loss of connection. In fact, his job could have created meaning for him. Additionally, Hector had also faced instances of discrimination, which decreases the possibility of a climate of safety.

Practitioners can discuss with Chris and Hector the implications of discrimination toward their health. Practitioners can highlight factors and social determinants involved in explicit and implicit effects of discrimination on wellness and domains of health (e.g., physical, financial, social). Practitioners can also highlight instances of subordination, where Chris and Hector may have been subjugated to another person's harmful comments.

Practitioners can accentuate the manner in which Chris and Hector bring their own responses to stigma from affectional, sexual, and racial discrimination on individual and intimate partner levels. Similarly, practitioners can highlight how their own social identities play a role in power differentials with Chris and Hector together as a couple and as individuals. Practitioners can also understand their own responses to oppression and how they might transfer the experience to professional counseling relationships (e.g., internalized oppression). In some cases, practitioners might eschew from broaching cultural factors and discriminatory experiences due to internalized oppression. Practitioners can also use themselves as a model or tool when considering power differentials or uneven tensions of privilege and oppression.

Note. Table 1 demonstrates applications of RCT principles supplemented by conceptual and empirical literature. The principles are directly linked to potential avenues in the case example. 
As demonstrated in the case example and Table 1, professional counselors can use RCT to strengthen an awareness of structural and interpersonal forms of oppression affecting older LGBTQ+ adults of color. With the combination of life transitions and convergent forms of oppression, Chris and Hector may become more disconnected from each other, society, or other personal relationships. The effects of oppression can culminate in a longstanding experience of disconnection. Under the RCT lens, professional counselors can identify how oppression (e.g., racism, heterosexism) exacerbates feelings of disconnection and impacts the overall health of relationships (Singh et al., 2020; Singh \& Moss, 2016). It is possible that Chris might be contending with prior experiences of relational images that potentially invoke stigma and familial histories with discrimination. Consistent with Table 1, professional counselors can demonstrate how prior interpersonal experiences of marginalization can result in feelings of isolation within Chris and Hector's relationship and silence around their concerns.

As Chris and Hector navigate life transitions and aging, professional counselors can illustrate how physical and mental health draw upon the strength of relationships, especially for communities facing social isolation (Mereish \& Poteat, 2015; Woody, 2014, 2015). Tenets of RCT also focus on relational growth and resilience, which reflect how professional counselors can use strengths, growth, and creativity to ameliorate the cumulative effects of marginalization (Comstock et al., 2008; Hammer et al., 2014, 2016). By infusing these elements in practice, professional counselors invoke the Five Good Things (Miller, 1976; Miller \& Stiver, 1997), which can apply to Chris and Hector's relationship and transfer to other personal relationships. Although professional counselors can contextualize the experience of oppression, focusing on the strengths of Chris and Hector's relationship can highlight how they have historically relied on each other and other community members for support. Reflecting on experiences of resilience and oppression can elicit more nuanced meaning in their relationship and identify possibilities for growth.

\section{Future Research Directions for RCT With Older LGBTQ+ Adults of Color}

Considering the overall framework of RCT in application to older LGBTQ+ adults of color, gerontological counseling researchers can explore a variety of avenues to advance research agendas and bridge the gap across these intersecting social identities. Counseling researchers can employ quantitative and qualitative analyses pertaining to older LGBTQ+ adults of color to challenge relational images perpetuated by society (Duffey \& Somody, 2011; Hammer et al., 2016). More importantly, research framed within principles of RCT can also yield more in-depth understanding of how older LGBTQ+ adults of color navigate resilience, empowerment, and incidents of oppression, which are foundational to intersectionality and the RCT approach (Duffey \& Trepal, 2016; Haskins \& Appling, 2017; Singh et al., 2020). This emphasis is especially critical for older LGBTQ+ adults of color who are less likely to seek counseling that fails to affirm their identity (Kim et al., 2017; Singh \& Moss, 2016). As researchers have continued to emphasize a stronger focus on resilience with multiply marginalized communities (Bostwick et al., 2014; Bower et al., 2021; Singh, 2013), RCT presents a useful framework for identity affirmation because of its focus on authenticity and growth-fostering connections (Flores \& Sheely-Moore, 2020; Mereish \& Poteat, 2015). As several gerontological and health equity researchers have documented, identity affirmation and culturally responsive care are crucial for buffering negative health care experiences that prevent historically marginalized clients from seeking help (Flynn et al., 2020; Fredriksen-Goldsen et al., 2017; Howard et al., 2019; Kim et al., 2017). Associated with advances of research in intersectionality, RCT continues to demonstrate promising opportunities for the critical examination of linked social identities that mirror multiple overlapping forms of oppression (Addison \& Coolhart, 2015; Chan \& Erby, 2018; Singh \& Moss, 2016). As a theoretical framework, RCT can contextualize how structural forms of oppression (e.g., racism, ageism, heterosexism) converge for 
older LGBTQ+ adults of color, given RCT's underpinnings in equity, social context, action, and a social justice agenda (Singh et al., 2020). As researchers have noted, oppression relates to physical and mental health disparities, covers a number of social experiences (e.g., social isolation, help-seeking, caregiving), and is connected to relational well-being (Correro \& Nielson, 2020; Jones et al., 2018; Kim et al., 2017; Seelman et al., 2017).

\section{Infusing RCT Constructs in Research}

Gerontological counseling researchers can apply many of the RCT constructs to foster research questions to expand RCT's applicability beyond a theoretical framework, such as feelings of empowerment and attitudes toward relationships and growth. Additionally, research has not predominantly involved RCT for empirical use, although RCT is consistently taken up through theoretical applications in practice (Haskins \& Appling, 2017; Jordan \& Carlson, 2013; Kress et al., 2018), education (Hammer et al., 2014), supervision (Lenz, 2014), and advising (Purgason et al., 2016). It has been used particularly as a rich theoretical framework to reform critical thinking in practice. However, the implementation of RCT can immensely benefit from furthering an empirical base to create more accessibility with applying such methods in counseling practice (Lenz, 2016). If counseling practitioners implement RCT as part of their clinical approaches, research studies would be particularly useful if research questions targeted how RCT is successful specifically with older LGBTQ+ adults of color. Because RCT is relationally driven, researchers can integrate measures on relationships as outcome variables that might explain a moderated effect, particularly if identity disaffirmation or specific forms of oppression (e.g., racism, ageism) are contributing to lower outcomes of wellness. In this case, the strength of relational outcomes may weaken the relationship between multiple measures of oppression and wellness. This information would continue to highlight which RCT factors need further intervention and effectiveness research to inform its utility as a culturally responsive practice model.

\section{RCT in Quantitative Design}

Regarding methodological frameworks, researchers can illustrate connections with RCT principles across multiple types of modalities and methods of research (e.g., quantitative, qualitative, mixedmethods). Components of RCT can more heavily exhibit factors and variables involved in the RCT lens, such as relational capacity and growth. This premise is especially vital for researchers concerned with building measurements to advance clinical practice and knowledge. Aside from the work of Liang and colleagues (2002), measures of RCT factors are virtually nonexistent, and they have not been normed for a myriad of samples connected to older LGBTQ+ adults of color. Thus, researchers can incorporate RCT into applied research with older LGBTQ+ adults of color and underscore its applicability and empirical relevance for gerontological practice. Considering Lenz's (2016) argument for the relevance of RCT as a useful approach within practice and intervention research, it is necessary to expand research studies that observe how counseling practitioners can implement the approach of RCT with older LGBTQ+ adults of color.

\section{RCT in Qualitative Design}

Vital for research designs grounded in qualitative research, RCT can be used as a framework aligned with certain paradigms (Creswell \& Poth, 2018; Guba \& Lincoln, 1994; Merriam \& Tisdell, 2016). The use of RCT is its own phenomenon, but it can also serve as a vehicle integrated into the paradigm of a particular qualitative research study, such as exploring grief and loss with older LGBTQ+ adults of color. Qualitative research can function from interpretivist, feminist, critical, and intersectional paradigms (Chan \& Erby, 2018). Although the integration of RCT with feminist and critical paradigms are more likely due to explicit ties to social justice, the RCT approach can also 
be useful with interpretivist paradigms to examine how RCT reflects the lens of samples including older LGBTQ+ adults of color. Since the purpose, methodological decisions, and strategies for data analysis would follow an interpretivist approach, RCT can operate as the theoretical framework, especially to inform tools for data collection and procedures involved in data analysis. Reflecting on the lived experiences of older LGBTQ+ adults of color, counseling researchers can explore a multitude of research questions. For instance, qualitative researchers can examine the lived experiences of disconnection with access to health care providers in rural settings for older LGBTQ+ adults of color. Fundamental to RCT, another potential research question can highlight how older LGBTQ+ adults of color discover social supports and networks in older adulthood. Given the overlap in experiences with oppression, researchers can generate qualitative research that addresses how older LGBTQ+ adults of color have utilized their social supports to ameliorate racism, genderism, ageism, and heterosexism across the life span.

\section{Conclusion}

Given the history of discriminatory acts against LGBTQ+ communities, which can be compounded by the challenges individuals face as they age, RCT serves as an approach that acknowledges the various levels of oppression and serves as a strength-based framework to employ in a clinical setting (Comstock et al., 2008). This approach, in particular, highlights both contextual and systemic factors contributing to deepened levels of disconnection for older LGBTQ+ adults of color (Haskins \& Appling, 2017; Jordan \& Carlson, 2013; Singh \& Moss, 2016). Using components of RCT highlights the manner in which older LGBTQ+ adults of color have been disconnected from practitioners, social relationships, institutions, and society. Implementing the RCT approach brings forth new forms of critical thinking to emphasize interpersonal and contextual factors contributing to relational growth, equity, and connection. As counseling practitioners continue to broaden their perspectives through an RCT framework, the application of RCT must serve as a driving force for further empirical research showing the developmental connection between theory and practice with older LGBTQ+ adults of color.

\section{Conflict of Interest and Funding Disclosure}

The authors reported no conflict of interest or funding contributions for the development of this manuscript.

\section{References}

Addison, S. M., \& Coolhart, D. (2015). Expanding the therapy paradigm with queer couples: A relational intersectional lens. Family Process, 54(3), 435-453. https://doi.org/10.1111/famp.12171

Bockting, W., Coleman, E., Deutsch, M. B., Guillamon, A., Meyer, I., Meyer, W., III., Reisner, S., Sevelius, J., \& Ettner, R. (2016). Adult development and quality of life of transgender and gender nonconforming people. Current Opinion in Endocrinology, Diabetes, and Obesity, 23(2), 188-197. https://doi.org/10.1097/MED.0000000000000232

Bostwick, W. B., Meyer, I., Aranda, F., Russell, S., Hughes, T., Birkett, M., \& Mustanski, B. (2014). Mental health and suicidality among racially/ethnically diverse sexual minority youths. American Journal of Public Health, 104(6), 1129-1136. https://doi.org/10.2105/AJPH.2013.301749 
The Professional Counselor I Volume 11, Issue 3

Bower, K. L., Lewis, D. C., Bermúdez, J. M., \& Singh, A. A. (2021). Narratives of generativity and resilience among LGBT older adults: Leaving positive legacies despite social stigma and collective trauma. Journal of Homosexuality, 68(2), 230-251. https://doi.org/10.1080/00918369.2019.1648082

Brennan-Ing, M., Seidel, L., Larson, B., \& Karpiak, S. E. (2014). Social care networks and older LGBT adults: Challenges for the future. Journal of Homosexuality, 61(1), 21-52. https://doi.org/10.1080/00918369.2013.835235

Bryan, A. E. B., Kim, H.-J., \& Fredriksen-Goldsen, K. I. (2017). Factors associated with high-risk alcohol consumption among LGB older adults: The roles of gender, social support, perceived stress, discrimination, and stigma. The Gerontologist, 57(1), S95-S104. https://doi.org/10.1093/geront/gnw100

Chan, C. D. (2018). Families as transformative allies to trans youth of color: Positioning intersectionality as analysis to demarginalize political systems of oppression. Journal of GLBT Family Studies, 14(1-2), 43-60. https://doi.org/10.1080/1550428X.2017.1421336

Chan, C. D., \& Erby, A. N. (2018). A critical analysis and applied intersectionality framework with intercultural queer couples. Journal of Homosexuality, 65(9), 1249-1274. https://doi.org/10.1080/00918369.2017.1411691

Chan, C. D., \& Silverio, N. (in press). Issues for LGBTQ elderly. In K. L. Nadal \& M. Scharrón-del Río (Eds.), Queer psychology: Intersectional perspectives. Springer. https://doi.org/10.1007/978-3-030-74146-4

Chaney, M. P., \& Whitman, J. S. (2020). Affirmative wellness counseling with older LGBTQ+ adults. Journal of Mental Health Counseling, 42(4), 303-322. https://doi.org/10.17744/mehc.42.4.02

Choi, S. K., \& Meyer, I. H. (2016). LGBT aging: A review of research findings, needs, and policy implications. The Williams Institute. https://williamsinstitute.law.ucla.edu/publications/lgbt-aging

Cloyes, K. G. (2016). The silence of our science: Nursing research on LGBT older adult health. Research in Gerontological Nursing, 9(2), 92-104. https://doi.org/10.3928/19404921-20151218-02

Comstock, D. L., Hammer, T. R., Strentzsch, J., Cannon, K., Parsons, J., \& Salazar, G., II. (2008). Relationalcultural theory: A framework for bridging relational, multicultural, and social justice competencies. Journal of Counseling $\mathcal{E}$ Development, 86(3), 279-287. https://doi.org/10.1002/j.1556-6678.2008.tb00510.x

Correro, A. N., II., \& Nielson, K. A. (2020). A review of minority stress as a risk factor for cognitive decline in lesbian, gay, bisexual, and transgender (LGBT) elders. Journal of Gay E Lesbian Mental Health, 24(1), 2-19. https://doi.org/10.1080/19359705.2019.1644570

Creswell, J. W., \& Poth, C. N. (2018). Qualitative inquiry and research design: Choosing among five approaches (4th ed.). SAGE.

David, E. J. R., Schroeder, T. M., \& Fernandez, J. (2019). Internalized racism: A systematic review of the psychological literature on racism's most insidious consequence. Journal of Social Issues, 75(4), 10571086. https://doi.org/10.1111/josi.12350

Du, Y., \& Xu, Q. (2016). Health disparities and delayed health care among older adults in California: A perspective from race, ethnicity, and immigration. Public Health Nursing, 33(5), 383-394. https://doi.org/10.1111/phn.12260

Duffey, T. (2007). Promoting relational competencies in counselor education through creativity and relationalcultural theory. Journal of Creativity in Mental Health, 2(1), 47-59. https://doi.org/10.1300/J456v02n01_05

Duffey, T., Haberstroh, S., \& Trepal, H. (2009). A grounded theory of relational competencies and creativity in counseling: Beginning the dialogue. Journal of Creativity in Mental Health, 4(2), 89-112. https://doi.org/10.1080/15401380902951911

Duffey, T., \& Somody, C. (2011). The role of relational-cultural theory in mental health counseling. Journal of Mental Health Counseling, 33(3), 223-242. https://doi.org/10.17744/mehc.33.3.c10410226u275647

Duffey, T., \& Trepal, H. (2016). Introduction to the special section on relational-cultural theory. Journal of Counseling \& Development, 94(4), 379-382. https://doi.org/10.1002/jcad.12095

Dzierzewski, J. M. (2014). Diversity in late life: Definitions, implications, and considerations. Clinical Gerontologist, 37(1), 1-3. https://doi.org/10.1080/07317115.2014.847308

Flores, C. A., \& Sheely-Moore, A. I. (2020). Relational-cultural theory-based interventions with LGBTQ college students. Journal of College Counseling, 23(1), 71-84. https://doi.org/10.1002/jocc.12150

Flynn, P. M., Betancourt, H., Emerson, N. D., Nunez, E. I., \& Nance, C. M. (2020). Health professional cultural competence reduces the psychological and behavioral impact of negative healthcare encounters. Cultural Diversity and Ethnic Minority Psychology, 26(3), 271-279. https://doi.org/10.1037/cdp0000295 
Fredriksen-Goldsen, K. I. (2014). Promoting health equity among LGBT mid-life and older adults: Revealing how LGBT mid-life and older adults can attain their full health potential. Generations, 38(4), 86-92.

Fredriksen-Goldsen, K. I., Emlet, C. A., Kim, H.-J., Muraco, A., Erosheva, E. A., Goldsen, J., \& Hoy-Ellis, C. P. (2013). The physical and mental health of lesbian, gay male, and bisexual (LGB) older adults: The role of key health indicators and risk and protective factors. The Gerontologist, 53(4), 664-675.

https://doi.org/10.1093/geront/gns123

Fredriksen-Goldsen, K. I., Kim, H.-J., Bryan, A. E., Shiu, C., \& Emlet, C. A. (2017). The cascading effects of marginalization and pathways of resilience in attaining good health among LGBT older adults. The Gerontologist, 57(S1), S72-S83. https://doi.org/10.1093/geront/gnw170

Fredriksen-Goldsen, K. I., Kim, H.-J., Shiu, C., Goldsen, J., \& Emlet, C. A. (2015). Successful aging among LGBT older adults: Physical and mental health-related quality of life by age group. The Gerontologist, 55(1), 154-168. https://doi.org/10.1093/geront/gnu081

Fullen, M. C. (2016). Counseling for wellness with older adults. Adultspan Journal, 15(2), 109-123. https://doi.org/10.1002/adsp.12025

Fullen, M. C. (2018). Ageism and the counseling profession: Causes, consequences, and methods for counteraction. The Professional Counselor, 8(2), 104-114. https://doi.org/10.15241/mcf.8.2.104

Fullen, M. C., Gorby, S., Chan, C. D., Dobmeier, R. A., \& Jordan, J. (2019). The current state of gerontological counseling research: A 26-year content analysis. Journal of Counseling E Development, 97(4), 387-397. https://doi.org/10.1002/jcad.12287

Fullen, M. C., Granello, D. H., Richardson, V. E., \& Granello, P. F. (2018). Using wellness and resilience to predict age perception in older adulthood. Journal of Counseling \& Development, 96(4), 424-435. https://doi.org/10.1002/jcad.12224

Fullen, M. C., Wiley, J. D., Jordan, J., Sharma, J., \& Lawson, G. (2020). “Heartbreaking” referrals, professional "disgrace": The impact of Medicare ineligibility on the counseling profession. Adultspan Journal, 19(1), 3-21. https://doi.org/10.1002/adsp.12084

Griffith, C., Akers, W., Dispenza, F., Luke, M., Farmer, L. B., Watson, J. C., Davis, R. J., \& Goodrich, K. M. (2017). Standards of care for research with participants who identify as LGBTQ+. Journal of LGBT Issues in Counseling, 11(4), 212-229. https://doi.org/10.1080/15538605.2017.1380549

Guba, E. G., \& Lincoln, Y. S. (1994). Competing paradigms in qualitative research. In N. K. Denzin \& Y. S. Lincoln (Eds.), Handbook of qualitative research (1st ed., pp. 105-117). SAGE.

Hammer, T., Trepal, H., \& Speedlin, S. (2014). Five relational strategies for mentoring female faculty. Adultspan Journal, 13(1), 4-14. https://doi.org/10.1002/j.2161-0029.2014.00022.x

Hammer, T. R., Crethar, H. C., \& Cannon, K. (2016). Convergence of identities through the lens of relationalcultural theory. Journal of Creativity in Mental Health, 11(2), 126-141. https://doi.org/10.1080/15401383.2016.1181596

Haskins, N. H., \& Appling, B. (2017). Relational-cultural theory and reality therapy: A culturally responsive integrative framework. Journal of Counseling $\mathcal{E}$ Development, 95(1), 87-99. https://doi.org/10.1002/jcad.12120

Hinrichs, K. L. M., \& Donaldson, W. (2017). Recommendations for use of affirmative psychotherapy with LGBT older adults. Journal of Clinical Psychology, 73(8), 945-953. https://doi.org/10.1002/jclp.22505

Howard, S. D., Lee, K. L., Nathan, A. G., Wenger, H. C., Chin, M. H., \& Cook, S. C. (2019). Healthcare experiences of transgender people of color. Journal of General Internal Medicine, 34(10), 2068-2074. https://doi.org/10.1007/s11606-019-05179-0

Jackson, S. D., Mohr, J. J., Sarno, E. L., Kindahl, A. M., \& Jones, I. L. (2020). Intersectional experiences, stigmarelated stress, and psychological health among Black LGBQ individuals. Journal of Consulting and Clinical Psychology, 88(5), 416-428. https://doi.org/10.1037/ccp0000489

Jones, R. M., Simpson, G. M., \& Stansbury, K. (2018). Informal support experiences of older African-American gay men living with HIV/AIDS. Journal of Gay E Lesbian Social Services, 30(3), 209-219. https://doi.org/10.1080/10538720.2018.1463886

Jordan, J. V. (2000). The role of mutual empathy in relational/cultural therapy. Journal of Clinical Psychology, 56(8), 1005-1016. https://doi.org/cfp6pr

Jordan, J. V. (2010). Relational-cultural therapy (1st ed.). American Psychological Association.

Jordan, J. V. (2017). Relational-cultural theory: The power of connection to transform our lives. The Journal of Humanistic Counseling, 56(3), 228-243. https://doi.org/10.1002/johc.12055 
Jordan, J. V., \& Carlson, J. (Eds.). (2013). Creating connection: A relational-cultural approach with couples. Routledge. Kampfe, C. M. (2015). Counseling older people: Opportunities and challenges. American Counseling Association.

Karpiak, S. E., \& Brennan-Ing, M. (2016). Aging with HIV: The challenges of providing care and social supports. Generations, 40(2), 23-25.

Kim, H.-J., Jen, S., \& Fredriksen-Goldsen, K. I. (2017). Race/ethnicity and health-related quality of life among LGBT older adults. The Gerontologist, 57(S1), S30-S39. https://doi.org/10.1093/geront/gnw172

Kimmel, D. (2014). Lesbian, gay, bisexual, and transgender aging concerns. Clinical Gerontologist, 37(1), 49-63. https://doi.org/10.1080/07317115.2014.847310

Kress, V. E., Haiyasoso, M., Zoldan, C. A., Headley, J. A., \& Trepal, H. (2018). The use of relational-cultural theory in counseling clients who have traumatic stress disorders. Journal of Counseling $\mathcal{E}$ Development, 96(1), 106-114. https://doi.org/10.1002/jcad.12182

Lecompte, M., Ducharme, J., Beauchamp, J., \& Couture, M. (2021). Inclusive practices toward LGBT older adults in healthcare and social services: A scoping review of quantitative and qualitative evidence. Clinical Gerontologist, 44(3), 210-221. https://doi.org/10.1080/07317115.2020.1862946

Lenz, A. S. (2014). Integrating relational-cultural theory concepts into supervision. Journal of Creativity in Mental Health, 9(1), 3-18. https://doi.org/10.1080/15401383.2013.864960

Lenz, A. S. (2016). Relational-cultural theory: Fostering the growth of a paradigm through empirical research. Journal of Counseling \& Development, 94(4), 415-428. https://doi.org/10.1002/jcad.12100

Liang, B., Tracy, A., Taylor, C. A., Williams, L. M., Jordan, J. V., \& Miller, J. B. (2002). The Relational Health Indices: A study of women's relationships. Psychology of Women Quarterly, 26(1), 25-35. https://doi.org/10.1111/1471-6402.00040

Mabey, J. E. (2011). Counseling older adults in LGBT communities. The Professional Counselor, 1(1), 57-62. https://doi.org/10.15241/jem.1.1.57

Mereish, E. H., \& Poteat, V. P. (2015). The conditions under which growth-fostering relationships promote resilience and alleviate psychological distress among sexual minorities: Applications of relational cultural theory. Psychology of Sexual Orientation and Gender Diversity, 2(3), 339-344. https://doi.org/10.1037/sgd0000121

Merriam, S. B., \& Tisdell, E. J. (2016). Qualitative research: A guide to design and implementation (4th ed.). Jossey-Bass.

Meyer, I. H. (2014). Minority stress and positive psychology: Convergences and divergences to understanding LGBT health. Psychology of Sexual Orientation and Gender Diversity, 1(4), 348-349. https://doi.org/10.1037/sgd0000070

Meyer, I. H. (2016). The elusive promise of LGBT equality. American Journal of Public Health, 106(8), 1356-1358. https://doi.org/10.2105/AJPH.2016.303221

Miller, J. B. (1976). Toward a new psychology of women (2nd ed.). Beacon Press.

Miller, J. B., \& Stiver, I. P. (1997). The healing connection: How women form relationships in therapy and in life. Beacon Press.

Porter, K. E., Brennan-Ing, M., Chang, S. C., dickey, 1. m., Singh, A. A., Bower, K. L., \& Witten, T. M. (2016). Providing competent and affirming services for transgender and gender nonconforming older adults. Clinical Gerontologist, 39(5), 366-388. https://doi.org/10.1080/07317115.2016.1203383

Purgason, L. L., Avent, J. R., Cashwell, C. S., Jordan, M. E., \& Reese, R. F. (2016). Culturally relevant advising: Applying relational-cultural theory in counselor education. Journal of Counseling \& Development, 94(4), 429-436. https://doi.org/10.1002/jcad.12101

Rausch, M. A., \& Wikoff, H. D. (2017). Addressing concerns with lesbian couples experiencing fertility treatment: Using relational cultural theory. Journal of LGBT Issues in Counseling, 11(3), 142-155. https://doi.org/10.1080/15538605.2017.1346494

Robinson-Wood, T., \& Weber, A. (2016). Deconstructing multiple oppressions among LGBT older adults. In D. A. Harley \& P. B. Teaster (Eds.), Handbook of LGBT elders: An interdisciplinary approach to principles, practices, and policies (pp. 65-81). Springer.

Rowan, N. L., \& Giunta, N. (2016). Lessons on social and health disparities from older lesbians with alcoholism and the role of interventions to promote culturally competent services. Journal of Human Behavior in the Social Environment, 26(2), 210-216. https://doi.org/10.1080/10911359.2015.1083504 
Seelman, K. L. (2019). Differences in mental, cognitive, and functional health by sexual orientation among older women: Analysis of the 2015 Behavioral Risk Factor Surveillance System. The Gerontologist, 59(4), 749-759. https://doi.org/10.1093/geront/gnx215

Seelman, K. L., Adams, M. A., \& Poteat, T. (2017). Interventions for healthy aging among mature Black lesbians: Recommendations gathered through community-based research. Journal of Women $\mathcal{E}$ Aging, 29(6), 530-542. https://doi.org/10.1080/08952841.2016.1256733

Singh, A. A. (2013). Transgender youth of color and resilience: Negotiating oppression and finding support. Sex Roles, 68(11), 690-702. https://doi.org/10.1007/s11199-012-0149-z

Singh, A. A., Appling, B., \& Trepal, H. (2020). Using the Multicultural and Social Justice Counseling Competencies to decolonize counseling practice: The important roles of theory, power, and action. Journal of Counseling \& Development, 98(3), 261-271. https://doi.org/10.1002/jcad.12321

Singh, A. A., \& Moss, L. (2016). Using relational-cultural theory in LGBTQQ counseling: Addressing heterosexism and enhancing relational competencies. Journal of Counseling $\mathcal{E}$ Development, 94(4), 398-404. https://doi.org/10.1002/jcad.12098

South, K. T. (2017). The impact of public policy on LGBT aging. Annual Review of Gerontology E Geriatrics, 37(1), 161-174. https://doi.org/10.1891/0198-8794.37.161

Sue, D. W., Sue, D., Neville, H. A., \& Smith, L. (2019). Counseling the culturally diverse: Theory and practice (8th ed.). Wiley.

Trepal, H. C., Boie, I., \& Kress, V. E. (2012). A relational cultural approach to working with clients with eating disorders. Journal of Counseling \& Development, 90(3), 346-356. https://doi.org/10.1002/j.1556-6676.2012.00043.x

Van Sluytman, L. G., \& Torres, D. (2014). Hidden or uninvited? A content analysis of elder LGBT of color literature in gerontology. Journal of Gerontological Social Work, 57(2-4), 130-160. https://doi.org/10.1080/01634372.2013.877551

Veldhuis, C. B., Talley, A. E., Hancock, D. W., Wilsnack, S. C., \& Hughes, T. L. (2017). Alcohol use, age, and selfrated mental and physical health in a community sample of lesbian and bisexual women. LGBT Health, 4(6), 419-426. https://doi.org/10.1089/lgbt.2017.0056

Velez, B. L., Polihronakis, C. J., Watson, L. B., \& Cox, R., Jr. (2019). Heterosexism, racism, and the mental health of sexual minority people of color. The Counseling Psychologist, 47(1), 129-159. https://doi.org/10.1177/0011000019828309

Walker, M., \& Rosen, W. B. (Eds.). (2004). How connections heal: Stories from relational-cultural therapy. Guilford.

Woody, I. (2014). Aging out: A qualitative exploration of ageism and heterosexism among aging African American lesbians and gay men. Journal of Homosexuality, 61(1), 145-165. https://doi.org/10.1080/00918369.2013.835603

Woody, I. (2015). Lift every voice: Voices of African-American lesbian elders. Journal of Lesbian Studies, 19(1), 50-58. https://doi.org/10.1080/10894160.2015.972755

Yarns, B. C., Abrams, J. M., Meeks, T. W., \& Sewell, D. D. (2016). The mental health of older LGBT adults. Current Psychiatry Reports, 18(6), 1-11. https://doi.org/10.1007/s11920-016-0697-y 